\title{
CAPOEIRA NAS AULAS DE EDUCAÇÃO FÍSICA: UMA PROPOSTA DE INTERVENÇÃO*
}

\author{
Flávia Dayana Almeida Noronha* * \\ Rúbia-Mar Nunes Pinto***
}

\section{RESUMO}

$\mathrm{O}$ artigo apresenta os resultados de uma pesquisa na qual procuramos dialogar com o conhecimento da capoeira no sentido de propor estratégias de intervenção para o seu trato nas aulas de Educação Física nos primeiros anos de escolarização. Procuramos trabalhar, de maneira articulada, os elementos teóricos e práticos que compõem o universo desta manifestação cultural, os quais foram sistematizados na forma de seqüenciador de aulas a partir de sete temáticas norteadoras: luta, localização geográfica, música, corpo, forma de organização social, fundamentos e capoeira e luta. Ao final, compreendemos algumas questões importantes no que se refere à metodologia empregada e ao entendimento do processo de desenvolvimento da criança.

PALAVRAS-CHAVE: educação - educação física - capoeira - proposta pedagógica trato com o conhecimento.

* Este artigo é uma síntese da monografia com o mesmo título apresentada no curso de Especialização em Educação Física Escolar da Faculdade de Educação Física da Universidade Federal de Goiás.

** Especialista em Educação Física Escolar e Professora da Rede Municipal de Ensino de Goiânia.

*** Professora mestra da Faculdade de Educação Física da Universidade Federal de Goiás e orientadora do trabalho monográfico mencionado. 


\title{
INTRODUÇÃO
}

\section{CAPOEIRA E A VALORIZAÇÃO DA IDENTIDADE NEGRA: ALGUMAS REFLEXÕES}

\begin{abstract}
A capoeira é uma manifestação popular que possui um importante registro histórico na corporeidade brasileira, representando modos de ser de nossos antepassados africanos. Estes povos, que para cá vieram na condição de escravos, foram submetidos a um processo desumano e exploratório de suas capacidades. Diante desta situação, utilizando-se de elementos de sua cultura de origem, criaram estratégias para resistir e lutar contra o sistema que os oprimia. Nesse contexto, situamos a Capoeira. Um misto de luta, dança e jogo, que se materializou como uma arma na busca pela liberdade.

Esta manifestação cultural, ao longo da história de nosso País, sofreu modificações na sua constituição, na maneira de se interpretá-la, praticá-la e difundi-la, acompanhando mudanças políticas, econômicas e sociais. Foi considerada de contravenção penal a símbolo da identidade nacional. Devido à sua origem no interior das senzalas, com raízes na cultura africana, e por ser a maioria de seus praticantes negros, durante o período Imperial e princípio da República, sua prática foi considerada contravenção penal. Desta condição foi criminalizada e incorporada ao Código Penal (1890), destacando mais uma vez a posição do negro na sociedade como ameaça à ordem e aos cidadãos de bem. Assim atravessou a mudança de regime, de Monarquia a República, até meados de 1930 quando se instalou no país uma política nacionalista comandada por Getúlio Vargas (REIS, 1997).

Naquele momento a manifestação da capoeira foi legalizada, podendo ser praticada em ambientes fechados, passando a ser tratada como ginástica nacional, símbolo da cultura brasileira. $\mathrm{O}$ ensino e a prática da capoeira, conforme propunha o ideário nacionalista, viriam a colaborar com a disciplinarização e docilização do corpo, bem como com a sua moralização, uma vez que estava vinculada à área da Educação Física, a qual nessa época recebia forte influência das instituições militar e médica. Ainda concordando com Reis,
\end{abstract}

[...] a construção da legitimidade da capoeira tem a ver com a construção do lugar social do negro no Brasil. Sendo assim, o significado social dessa prática cultural negra transmuta-se e atualiza-se conforme se operam

124 NORONHA, F. D. A.; NUNES PINTO, R. Capoeira nas aulas de educação... 
mudanças em relação às formas de percepção e inserção do negro na sociedade mais ampla (REIS,1997, p. 244).

De sua gênese surgiram duas linguagens, uma conhecida como Luta Regional Baiana (atualmente, apenas Capoeira Regional) e a outra como Capoeira Angola. No nosso entendimento, estas representam formas de agir na sociedade, podendo significar mais um elemento de alienação e controle social conforme a orientação do mercado e da indústria cultural ou, ao contrário, um elemento de valorização de nossa ancestralidade africana, como uma manifestação popular voltada para a leitura e compreensão da realidade com possibilidades de transformá-la. Assim, concordamos com Frigério (1989, p. 91) que "como toda atividade de origem popular, não codificada, existem diferentes concepções em torno do que ela é, e de como deve ser praticada e ensinada". E neste contexto, nos perguntamos: quais as possibilidades de a capoeira, no espaço escolar, ser inserida como componente curricular das aulas de Educação Física?

Tendo como referência o nosso envolvimento com a Capoeira Angola, procuramos elencar temáticas que pudessem exprimir a amplitude do ensino da capoeira nas aulas de Educação Física na escola, tais como:

a) A valorização da ancestralidade africana, a partir de uma visão de mundo que busca a compreensão do ser humano enquanto totalidade, não fragmentando suas dimensões corporal, estética, produtiva, religiosa, etc., visão que se materializa na roda de capoeira;

b) A forma de compreensão da organização de sua prática, a qual respeita uma hierarquia que se constrói com base na experiência de seu praticante, valorizando a sabedoria adquirida ao longo de sua prática, sendo esta reconhecida pela comunidade na qual está inserida, dispensando o uso de cordéis;

c) A compreensão do jogo enquanto um momento de diálogo, no qual se estabelece uma relação de pergunta e resposta, respeitando os limites e possibilidades de cada um(a);

d) A representação ritualística, musical e gestual, enquanto contribuições da expressão do legado africano à construção de uma consciência negra; e

e) $\mathrm{O}$ desenvolvimento de um sentimento de pertencimento, de forma a possibilitar a construção de uma relação de identidade 
entre seus praticantes, os quais se interagem a partir de ideais comuns, visando uma ação coletiva.

Por isso, percebemos a necessidade de compreender as possibilidades pedagógicas da capoeira nas aulas de Educação Física, promovendo a inter-relação entre estes elementos, que consideramos relacionados ao universo simbólico desta manifestação, e àqueles de ordem concreta que compõem a sua prática, tais como sua historicidade, seus movimentos e golpes. Almejávamos, assim, possibilitar às crianças o acesso a mais esta prática da cultura corporal, procurando

[...] desencadear um processo de pensamento - reflexão - ação daqueles que produzem a cultura popular, perceberem sua condição de sujeitos nesta produção de conhecimentos, possibilitando ampliarem suas referências sobre o mundo, valorizando aquilo que possui significado no seu cotidiano, enquanto importantes elementos de resistência e transformação da realidade social (NORONHA, 2002, p. 51).

Sobretudo, temos que nos atentar para a realidade na qual nos inserimos, considerando que nossos alunos precisam ter valorizado sua raiz cultural para além da ótica européia, como condição para se manifestarem diante dos condicionantes colocados por esta realidade. Precisam conhecer e interagir com os diversos conhecimentos oriundos da cultura afro-brasileira, mesmo porque, historicamente estes ou vêm sendo negados ou transmutados como é o caso da capoeira mestiça. De acordo com Nascimento (apud SANTOS, 2003: 35), "o sistema de ensino brasileiro pregou e ainda prega uma educação formal de embranquecimento cultural em sentido amplo. A educação formal não é só eurocentrista e de ostentação dos Estados Unidos, como também desqualifica a África e inferioriza racialmente os negros".

Nesta perspectiva, pensamos que seja de fundamental relevância, quando se trata da possibilidade de construção de uma identidade sóciocultural, debater sobre as contribuições da cultura africana para a formação do povo brasileiro. Temos que superar a postura omissa e depreciativa assumida diante da figura humana negra já que, conforme Araújo (2003, p. 218), "como resultado, este carimbo histórico confinou, entre outras coisas, os saberes de matriz africana na ingenuidade passiva da folclorização ou na periferia ativa da marginalização, descaracterizando os seus referenciais

126 NORONHA, F. D. A.; NUNES PINTO, R. Capoeira nas aulas de educação... 
estratégicos de sobrevivência histórica". Portanto, consideramos salutar a contribuição que o estudo sobre a capoeira pode desencadear no processo de construção da identidade sócio-cultural de nossos alunos, na medida em que consideramos a possibilidade de a capoeira,

[...] reunir na sua história os reflexos dos vários entendimentos políticos sobre a presença dos africanos e seus descendentes brasileiros [o que] pode nos ajudar a entender parte da trajetória de resistências destes numa realidade que sempre lhes fora hostil, o que significa dizer que aspectos da cultura também podem auxiliar professores(as) e educadores(as) a trabalharem sobre os movimentos de aceitação/rejeição desses aportes na formação de nossa chamada cultura e identidades nacionais (ARAÚJO, 2003, p. 230).

\section{A CAPOEIRA COMO CONTEÚdO NAS AULAS DE EDUCAÇÃO FÍSICA}

A escola pública que se consolidou em nossa sociedade tem como uma de suas características marcantes a negação ao saber popular e a valorização ao saber erudito, em função da necessidade de alfabetizar, civilizar e formar cidadãos aptos a viver em sociedade. Neste sentido, a disciplinarização do corpo assume papel de centralidade na dinâmica escolar, de forma a garantir uma "[...] redução das práticas culturais e políticas do conjunto da população não-escolarizada a folclore e/ou a manifestações perigosas de grupos ignorantes" (FARIA FILHO, 1997: 45).

Ainda de acordo com Faria Filho (1997), a escola trabalha a corporeidade para a ordem e a disciplina e, mesmo com toda a organização escolar voltada para este contento, a disciplina da Educação Física vem assumindo explicitamente esta tarefa. Neste sentido, a mesma compartilharia da lógica de negar o saber popular e fortalecer práticas sistematizadas que conduzam à educação do corpo como princípio de rendimento e contenção, um corpo controlado e eficiente.

Conforme Vago (1997), a introdução da Educação Física nas séries iniciais, no início do século XX, viria a colaborar para o ajustamento das crianças ao modo de vida urbana, tendo em vista o contexto do processo de industrialização. Caberia à Educação Física promover o ajustamento de condutas, padronizando comportamentos, preparando a futura mãode-obra e compensando desgastes provenientes do trabalho precoce, seja prevenindo ou corrigindo. De lá para cá, a Educação Física vem se 
fortalecendo enquanto responsável pela promoção do desenvolvimento motor, de capacidades físicas e modelos de comportamento, sofrendo influências de teorias assentadas nos campos da biologia e da psicologia, tendo como objetivo "... fabricar corpos submissos e corpos dóceis, regulando o espaço, o tempo e as normas a serem cumpridas pelos alunos" (VAGO, 1997, p. 71).

Assim, a Educação Física tem assumido um caráter ora disciplinador do comportamento, ora compensatório do desgaste produzido pela rotina escolar, ou ainda utilitário, servindo como suporte às demais áreas de conhecimento, quando se trata da aprendizagem nas séries iniciais. Essa lógica contém três momentos organicamente relacionados. Primeiramente, a Educação Física prepara para o conteúdo formalizado pela escola; em seguida obtém e controla o comportamento desejado das crianças no processo de aprendizagem por meio de um mecanismo de negociação, em que ela adquire um valor de troca, muito superior ao seu valor de uso; e, finalmente, ela compensa os efeitos negativos do exercício da aprendizagem, tornando-se um espaço de reconstituição das energias das crianças (VAGO, 1997, p. 80).

No nosso entendimento, a escola precisa promover contextos de conhecimento e vivências de manifestações populares com o intuito de promover a perpetuação do conhecimento assim como o debate sobre suas possibilidades de contribuição para a construção da identidade sócio-cultural dos sujeitos envolvidos. Cabe salientar, a necessidade de contextualização destas manifestações no interior da realidade na qual a escola se localiza. Vago (1997) sugere algumas possibilidades para a Educação Física no contexto escolar como a elaboração de propostas curriculares que considerem as necessidades da comunidade escolar e sua realidade; a ampliação da compreensão de corpo humano para além da sua dimensão biológica; a superação do entendimento da Educação Física atrelada a psicomotricidade; e a compreensão de um eixo curricular da Educação Física pautado em pressupostos culturais e históricos, entre as mais significativas.

Neste sentido, a capoeira, como uma manifestação cultural brasileira com raízes na cultura africana precisa ser contemplada nas aulas de Educação Física na escola como um conteúdo que contribua para a formação das crianças. Desta forma, é imprescindível que seus aspectos teórico-práticos sejam considerados de forma integrada e em codependência em relação aos aspectos subjetivos. Alguns autores vêm 
debatendo a presença da capoeira na escola, principalmente, pelo viés da Educação Física, seja como componente curricular ou como projeto extracurricular. Entre eles encontram-se Pinho (1993), Bastos (1999), Castro Jr. \& Abib (1999) e Silva (2001). Muito se tem debatido sobre as possibilidades pedagógicas da capoeira, destacando-a, inclusive como elemento possibilitador de construção de identidade.

O que pudemos observar, a partir de alguns anos de experiência com processos pedagógicos envolvendo a Capoeira, sobretudo junto a crianças e adolescentes provenientes de um nível sócio-econômico mais baixo, é que um dos elementos que mais tem servido como indicador da importância desse trabalho, reside justamente na valorização da identidade e da autoestima desses jovens (incluindo-se também aí os adultos) que ao se integrarem ao universo da Capoeira, começam a estabelecer uma relação mais próxima com a história de seu povo, de sua cultura e conseqüentemente, de sua idiossincrasia (CASTRO JR. \& ABIB, 1999, p. 179).

Desta maneira, nos deparamos com o desafio em experimentar possibilidades pedagógicas para a capoeira como um conteúdo a ser tematizado nas séries iniciais de forma a repensarmos nossa prática em busca de novas alternativas para o trato da capoeira na escola, e também, possibilitar o acesso a este conhecimento de matriz africana. Procuramos, assim, fortalecer este campo de pesquisa e contribuir com aqueles/as que pretendam tratar desta temática nas aulas de Educação Física na escola.

\section{O PENSAR E O FAZER CAPOEIRA NAS AULAS DE EDUCAÇÃO FÍSICA}

A elaboração de nossas intervenções se deu com a estruturação de um sequienciador de aulas, com base na orientação de Palafox et al (2002). Este referencial coloca como uma das diretrizes para a intervenção em Educação Física Escolar, "[...] a busca do estabelecimento de uma relação dialética de indissociabilização entre teoria e prática, tendo em vista a transformação político-pedagógica do processo de intervenção dos/as professores/as de Educação Física no contexto escolar" (PALAFOX et al., 2002, p. 25). Consideramos também outras contribuições na referida obra, tais como: a) avaliação constante do contexto social com base em aspectos particulares, imediatos, afetivos [...]; b) compreensão das dimensões afetivas e imaginárias do ser humano; c) incorporação de conceitos 
dialéticos - materialistas; d) promoção de processos de ensino aprendizagem, orientados para a produção do conhecimento com relevância social, com fundamento na práxis.

Aliados a estas, buscamos alguns pressupostos da escola de Vigotsky et al (1988) sobre a concepção do desenvolvimento da psique infantil. Segundo esta teorização, existem algumas forças que motivam o desenvolvimento da psique infantil e em cada fase do desenvolvimento umas agem mais diretamente do que outras. Neste sentido, esses autores apontam que a entrada da criança na escola produz um salto no seu desenvolvimento na medida em se ampliam as suas relações sociais e ela assume responsabilidades que antes não possuía, como a de estudar. Podemos dizer então, que a relação com o conhecimento sistematizado contribui significativamente para o desenvolvimento da criança.

Neste sentido, Leontiev (1988) afirma que, em cada fase do desenvolvimento, existem atividades consideradas principais. Estas são as que impulsionam o desenvolvimento, não pela freqüência com que são realizadas, mas pela importância atribuída a elas pela criança. " [...] podemos dizer que cada estágio do desenvolvimento psíquico caracterizase por uma relação explícita entre a criança e a realidade principal naquele estágio e por um tipo preciso de dominante de atividade" (LEONTIEV, 1988, p. 64).

No período pré-escolar a atividade principal da criança é a brincadeira do faz de conta, caracterizada, principalmente pela situação imaginária. Nesta atividade, a criança "[...] assimila o mundo objetivo como um mundo de objetos humanos reproduzindo ações humanas com eles" (IDEM, p. 59).

Já no período escolar, a atividade principal é o estudo sistematizado, sendo que o jogo torna-se atividade secundária. Ressalte-se que o jogo com regras já se faz presente, o qual contribui para o processo de abstração impulsionado pelo estudo sistematizado. Cabe destacar aqui que o conteúdo de cada estágio depende das condições concretas nas quais ocorre o desenvolvimento e conforme se operam mudanças nas relações sociais mais amplas. Conforme Leontiev,

[...] a mudança do tipo principal de atividade e a transição da criança de um estágio de desenvolvimento para outro correspondem a uma necessidade interior que está surgindo, e ocorre em conexão com o fato de a 
criança estar enfrentando a educação com novas tarefas correspondentes as suas potencialidades em mudança e uma nova percepção (LEONTIEV, 1988, p. 67).

Como o nosso universo se compõe, basicamente, de crianças em início do processo de escolarização, procuramos considerar também o papel da imitação e do brinquedo no processo de desenvolvimento, agora não como atividade principal, mas como aliados neste processo. Outro fator que consideramos relevante para o desenvolvimento de nossa pesquisa é a compreensão do conceito de zona de desenvolvimento proximal, o qual é desenvolvido por Vigotsky et al (1988). Assim, podemos considerar a zona de desenvolvimento proximal como sendo o caminho percorrido no desenvolvimento de funções que estão em processo de amadurecimento e que se consolidarão. Para tal, precisamos considerar o nível de desenvolvimento real e potencial. O primeiro se converte na capacidade autônoma de a criança realizar tarefas e o segundo se caracteriza pela ajuda do outro (adulto ou criança mais experiente) para que a criança consiga realizar tarefas. Diante disto, priorizamos em nossas intervenções atividades coletivas e/ou direcionadas por nós, para que pudéssemos trabalhar na zona de desenvolvimento proximal das crianças.

Quanto ao processo de imitação e da utilização do brinquedo como importantes elementos no processo de aprendizagem da criança, tomamos como atividade imitativa o processo de reconstrução individual daquilo que é observado nos outros e que não se constitui como mera cópia. Buscamos o papel do brinquedo como um espaço de possibilidade de se desenvolver uma zona de desenvolvimento proximal na criança, quando esta vivencia situações reais para além da sua realidade. Aquilo que é vivido no cotidiano de forma natural e despercebida, no momento da brincadeira passa a ser entendido pela criança qual o seu papel naquela situação. Neste sentido, procuramos (re) criar atividades que proporcionassem a imitação e a vivência de situações imaginárias que compõem o universo da capoeira.

Para construirmos nossa base metodológica, primeiramente, buscamos junto a autores como os já citados e também Frigério (1989), Reis (1997) e Carvalho Jr. (1998), contribuições sobre a capoeira. Concomitantemente, nos embasamos em elementos extraídos da nossa participação no Grupo Angolerê - Capoeira Angola. Neste sentido, 
contamos com a colaboração de uma de suas integrantes e, também, professora da Rede Municipal de Educação, Janayna Nogueira Rodrigues. Com esta professora, planejamos as intervenções a serem realizadas no período de 27 de novembro a 23 de dezembro de 2003, totalizando vinte e uma intervenções.

Podemos considerar que a capoeira contém elementos objetivos e subjetivos, os quais não devem ser compreendidos de forma fragmentada, uma vez que um leva à existência do outro e assim se tornam um par dialético em correspondência. Para compreendermos nossa problemática, neste momento os tratamos em separado, considerando como elementos objetivos aqueles de ordem material, tais como os movimentos (ginga, aú, rabo-de-arraia, rasteira, negativa e etc.), a bateria composta por três berimbaus, dois pandeiros, um agogô, um reco-reco e um atabaque ${ }^{1}$ e, também, pela música que se divide em três momentos: ladainha, chula e corrido $^{2}$. Já os elementos subjetivos abarcam o universo simbólico da capoeira, o qual lida com a sua historicidade, e também, com o comportamento e valores de seus praticantes. Dentre eles podemos destacar a forma de se compreender o mundo, muito bem colocado por Zagatto.

O universo é compreendido como a grande unidade da vida, onde todas as coisas se inter-relacionam, não separando o sagrado do profano, a vida da morte, o produtor (o homem) de seu produto (ferramenta / arte). $\mathrm{O}$ universo contempla todas as forças sagradas que nele se movimentam (ZAGATTO, 2003, p. 17).

No nosso entendimento não podemos conceber esta manifestação popular, ou qualquer outro conhecimento da cultura corporal, reduzindo-o ao domínio do gesto motor. Vislumbramos a possibilidade de buscar uma visão integrada, superando a fragmentação entre o pensar e o fazer, pois todo conhecimento é carregado de significado histórico. E tratar destes conceitos é fundamental para uma visão de totalidade do mesmo. Neste sentido, procuramos elencar alguns eixos temáticos e seus respectivos objetivos, que poderiam nortear as nossas intervenções, os quais consideramos importantes tendo em vista a compreensão dos elementos subjetivos que compõem a capoeira. Estes se encontram no seqüenciador que se segue: 


\begin{tabular}{|c|c|c|c|c|}
\hline \multicolumn{5}{|c|}{ SEQÜENCIADOR - CAPOEIRA } \\
\hline TEMA & $\begin{array}{c}\text { TEMPO } \\
\text { E } \\
\text { TOTAL } \\
\text { DE } \\
\text { AULAS }\end{array}$ & OBJETIVOS & $\begin{array}{l}\text { PROCEDIMENTOS } \\
\text { METODOLÓGICOS }\end{array}$ & MATERIAIS \\
\hline LUTA & $\begin{array}{l}1 \mathrm{H} / 3 \\
\text { AULAS }\end{array}$ & $\begin{array}{l}\text { Problematizar } \\
\text { a tematica } \\
\text { luta, como } \\
\text { forma de } \\
\text { resistência. }\end{array}$ & $\begin{array}{l}\text { 1. Diagnóstico: } \\
\text { Atividade } \\
\text { Fotografia; } \\
\text { 2. Movimentos de } \\
\text { ataque e defesa: } \\
\text { meia-lua de frente e } \\
\text { negativa: Atividade } \\
\text { - arco-íris e la- } \\
\text { gartixa dorminhoca; } \\
\text { 3. Música: Atividade - } \\
\text { Representando a } \\
\text { letra da música "O } \\
\text { canto das três raças". }\end{array}$ & $\begin{array}{l}\text { 2. CD de } \\
\text { capoeira; } \\
\text { 3. CD Clara } \\
\text { Nunes e CD } \\
\text { de capoeira. }\end{array}$ \\
\hline $\begin{array}{l}\text { LOCALIZAÇÃO } \\
\text { GEOGRÁFICA }\end{array}$ & $\begin{array}{l}1 \mathrm{H} / 3 \\
\text { AULAS }\end{array}$ & $\begin{array}{l}\text { Proporcionar } \\
\text { a compreen- } \\
\text { são sobre a } \\
\text { origem } \\
\text { geográfica dos } \\
\text { povos da etnia } \\
\text { negra, } \\
\text { situando a } \\
\text { relação Brasil } \\
\text {-África no } \\
\text { mundo. }\end{array}$ & $\begin{array}{l}\text { 1. Jogo: Percurso } \\
\text { África - Brasil; } \\
\text { 2. Atividade: Captura } \\
\text { nas tribos; } \\
\text { 3. Movimentos: queda } \\
\text { de quatro e chapa de } \\
\text { cós-tas no chão. } \\
\text { Atividade: Encontro } \\
\text { dos animais: zebras e } \\
\text { caranguejos. } \\
\text { Músicas: "Angola, ê, } \\
\text { ê, Angola ê, á..." "Eu } \\
\text { vou pra Angola...". }\end{array}$ & $\begin{array}{l}\text { 1. } 05 \text { painéis, } \\
25 \text { bambolês. } \\
\text { 2. bambolês, } \\
\text { corda, giz e } \\
\text { peteca. } \\
\text { 3. CD de } \\
\text { Capoeira. }\end{array}$ \\
\hline AVALIAÇÃO & $\begin{array}{l}\text { 1H/1 } \\
\text { AULA }\end{array}$ & $\begin{array}{l}\text { Avaliar a } \\
\text { compreensão } \\
\text { sobre os } \\
\text { temas luta e } \\
\text { localização } \\
\text { geográfica. }\end{array}$ & $\begin{array}{l}\text { Sorteio de perguntas e } \\
\text { provas: }\end{array}$ & \\
\hline MÚSICA & $\begin{array}{l}1 \mathrm{H} / 4 \\
\text { AULAS }\end{array}$ & $\begin{array}{l}\text { Trabalhar } \\
\text { ritmos e } \\
\text { instrumentos } \\
\text { de origem } \\
\text { africana } \\
\text { presentes na } \\
\text { cultura } \\
\text { brasileira. }\end{array}$ & $\begin{array}{l}\text { 1. Apresentar os } \\
\text { ritmos: Afoxé/axé: } \\
\text { Atividade - Desfile e } \\
\text { roda de samba; } \\
\text { 2. Apresentar os } \\
\text { ritmos: Rap e } \\
\text { Reggae: Atividades } \\
\text { - Seqüência e } \\
\text { Trenzinho; } \\
\text { 3. Apresentação dos } \\
\text { instrumentos da }\end{array}$ & $\begin{array}{l}\text { 1. CD’s: } \\
\text { Olodum, } \\
\text { Clara Nunes } \\
\text { e Mestre } \\
\text { Caiçara; } \\
\text { 2. CD's } \\
\text { Coletânea } \\
\text { 3. Berimbau, } \\
\text { agogô, }\end{array}$ \\
\hline
\end{tabular}




\begin{tabular}{|c|c|c|c|c|}
\hline & & & $\begin{array}{l}\text { capoeira: Atividade } \\
\text { - Os instrumentos; } \\
\text { 4. Ritmo da Capoeira; } \\
\text { Ladainha, Chula e } \\
\text { corrido: Atividade } \\
\text { - A música da } \\
\text { Capoeira. }\end{array}$ & $\begin{array}{l}\text { recoreco, } \\
\text { agogô e } \\
\text { pandeiro. } \\
\text { 4. CD's de } \\
\text { Capoeira. }\end{array}$ \\
\hline CORPO & $\begin{array}{l}\text { 1H/3 } \\
\text { AULAS }\end{array}$ & \begin{tabular}{|l|} 
Trabalhar \\
aspectos da \\
corporalidad \\
e africana \\
que \\
influenciam a \\
cultura \\
brasileira e a \\
manifestação \\
da capoeira.
\end{tabular} & $\begin{array}{l}\text { 1. Expressão pelo } \\
\text { corpo: Ijexá: } \\
\text { Atividade - ginga } \\
\text { maluca; } \\
\text { 2. Atividade: Meu } \\
\text { olhar sobre o outro; } \\
\text { 3. Movimentos: aú e } \\
\text { sapinho e músicas: } \\
\text { "Pega esse nego..." } \\
\text { e "Dá, dá, dá no } \\
\text { nego...": Atividade } \\
\text { - Mundo virado. } \\
\end{array}$ & $\begin{array}{l}\text { 1. CD Clara } \\
\text { Nunes } \\
\text { 2. Papel A4, } \\
\text { jornais. } \\
\text { 3. CD de } \\
\text { Capoeira. }\end{array}$ \\
\hline AVALIAÇÃO & $\begin{array}{l}\text { 1H/1 } \\
\text { AULA }\end{array}$ & \begin{tabular}{|l|} 
Avaliar a \\
compreensão \\
sobre os \\
temas música \\
e corpo
\end{tabular} & $\begin{array}{l}\text { Atividade: Como é } \\
\text { essa pessoa? Desenho } \\
\text { e debate sobre a letra } \\
\text { da música. }\end{array}$ & \\
\hline $\begin{array}{l}\text { FORMA } \\
\text { ORG. SOCIAL }\end{array}$ & $\begin{array}{l}\text { 1H/3 } \\
\text { AULAS }\end{array}$ & $\begin{array}{l}\text { Promover } \\
\text { vivências } \\
\text { sobre a } \\
\text { forma de } \\
\text { organização } \\
\text { social } \\
\text { africana } \\
\text { antes e } \\
\text { depois da } \\
\text { escravidão. }\end{array}$ & $\begin{array}{l}\text { 1. História "Amigo do } \\
\text { Rei"; } \\
\text { 2. Atividade: Feitores } \\
\text { e Escravos; } \\
\text { 3. História "A vida de } \\
\text { Zumbi dos } \\
\text { Palmares"/ } \\
\text { movimentos: rabo- } \\
\text { de-arraia e } \\
\text { negativa. }\end{array}$ & $\begin{array}{l}\text { 1. Livro. } \\
\text { 3. Livro e CD } \\
\text { de Capoeira. }\end{array}$ \\
\hline FUNDAMENTOS & $\begin{array}{l}\text { 1H/3 } \\
\text { AULAS }\end{array}$ & $\begin{array}{l}\text { Trabalhar os } \\
\text { fundamentos } \\
\text { da capoeira } \\
\text { Angola, } \\
\text { diferencian- } \\
\text { do-os da } \\
\text { prática da } \\
\text { Capoeira } \\
\text { Regional. }\end{array}$ & \begin{tabular}{|l} 
1. Atividade: \\
organização da \\
roda: movimentos \\
trabalhados. \\
2. Movimentos de \\
ataque e defesa: \\
chapa de frente e \\
role jogo: \\
Atividade - \\
Pergunta-resposta; \\
3. Atividade: \\
Filme - "Pastinha, \\
uma vida pela \\
capoeira". \\
\end{tabular} & $\begin{array}{l}\text { 1.Instrumento } \\
\text { de capoeira. } \\
\text { 3. Filme e CD } \\
\text { de capoeira. }\end{array}$ \\
\hline
\end{tabular}

134 NORONHA, F. D. A.; NUNES PINTO, R. Capoeira nas aulas de educação... 


\begin{tabular}{|c|c|c|c|c|}
\hline AVALIAÇÃO & $\begin{array}{l}\text { 1H/1 } \\
\text { AULA }\end{array}$ & $\begin{array}{l}\text { Avaliar os } \\
\text { conteúdos } \\
\text { sobre } \\
\text { capoeira } \\
\text { apreendidos. }\end{array}$ & $\begin{array}{l}\text { Caracterizar os } \\
\text { desenhos e nomear os } \\
\text { movimentos; } \\
\text { Reprodução/construção } \\
\text { coletiva da música. }\end{array}$ & $\begin{array}{l}\text { Desenhos com } \\
\text { movimentos } \\
\text { de capoeira. }\end{array}$ \\
\hline $\begin{array}{l}\text { CAPOEIRA } \\
\text { E LUTA }\end{array}$ & $\begin{array}{l}1 \mathrm{H} / 2 \\
\text { AULAS }\end{array}$ & $\begin{array}{l}\text { Trabalhar as } \\
\text { relações entre } \\
\text { a capoeira e a } \\
\text { temática } \\
\text { "Luta". } \\
\text { Perceber os } \\
\text { movimentos } \\
\text { apreendidos. }\end{array}$ & $\begin{array}{l}\text { 1. Atividade - Roda de } \\
\text { experimentação e } \\
\text { de-bate; } \\
\text { 2. Atividade - Roda de } \\
\text { Encerramento. }\end{array}$ & $\begin{array}{l}\text { Registrar as } \\
\text { opiniões sobre } \\
\text { a capoeira } \\
\text { como luta. }\end{array}$ \\
\hline
\end{tabular}

Após concluirmos nossas intervenções chegamos a alguns apontamentos que consideramos significativos à efetivação de uma proposta metodológica do trato da capoeira tendo como eixo norteador a possibilidade de contribuir para a identidade sócio-cultural das crianças. Primeiramente, percebemos a importância e a dificuldade de trabalhar o conteúdo procurando promover a inter-relação entre os seus elementos simbólicos e concretos e, neste sentido, procuramos planejar atividades que contemplassem os aspectos subjetivos e objetivos da capoeira, compreendendo que ambos não se encontram separados, mas podem ser diferenciados quanto ao trato que se dá ao conhecimento.

Outro fator que consideramos importante é que para o desenvolvimento de uma proposta metodológica que trate não apenas da capoeira, mas de qualquer conhecimento com matriz africana, é necessário ir a fundo na história da África e dos povos africanos no Brasil. Neste sentido, não podemos nos deixar levar pela história que nos conta que os negros nasceram escravos. É preciso conhecer outra visão histórica para além da eurocêntrica e construirmos com os sujeitos outras possibilidades de interpretação de um fato histórico.

No entanto, entendemos que é possível desenvolver e construir uma proposta pedagógica para a capoeira nas aulas de Educação Física na escola dentro de uma perspectiva crítica que possibilite à criança compreender aquilo que está fazendo. Entretanto, temos que ter em mente ao pensarmos em tal desafio:

- O tempo pedagógico do qual dispomos;

- A necessidade de envolvimento de todos os sujeitos da comunidade escolar; 
- A necessidade de instrumentalização teórica;

- A capacidade de compreensão dos sujeitos sobre os conceitos a serem tratados.

Considerados estes fatores gostaríamos de ressaltar a importância em se tratar de conhecimentos sistematizados sobre as práticas corporais, possibilitando sua apropriação para uma possível construção de um novo conhecimento. Desta maneira, esperamos ter contribuído com a continuidade do constante processo de busca que é o conhecimento tanto das crianças que foram contempladas na pesquisa, quanto de professores / pesquisadores que desejem trabalhar com a capoeira como conteúdo de suas aulas.

Capoeira in Physical Education classes: A proposition for intervention

\begin{abstract}
This article presents the results of a research work in which we tried to interact with the knowledge within Capoeira in order to propose intervention strategies for its use in physical education classes in the early levels of schooling. We aimed at working in an articulate manner with the theoretical and practical elements that constitute the universe of this cultural manifestation, which were then systematized in the form of a class sequencer taken from seven fundamental themes: fighting, geographical location, music, the body, forms of social organization, fundamentals, and capoeira and fighting. As a result, we have understood some important issues regarding the methodology used in capoeira as well as the development process in children.
\end{abstract}

KEY-WORDS: education - physical education - capoeira - pedagogical practices dealing with knowledge.

Capoeira en las clases de Educación Física: Una propuesta de intervención

\title{
RESUMEN
}

El artículo presenta los resultados de una investigación en la cual buscamos dialogar con el conocimiento de la capoeira en el sentido de proponer estrategias de intervención para su trato en las clases de Educación Física en los primeros años de escolarización. Procuramos trabajar, de manera articulada, los elementos teóricos y prácticos que componen el universo de esta manifestación cultural, los cuales fueron sistematizados en forma de secuenciador de clases a partir de siete temáticas norteadoras: lucha, localización geográfica, música, cuerpo, forma de organización social, fundamentos y capoeira y lucha. $\mathrm{Al}$ final, comprendemos algunas cuestiones importantes en lo que se refiere a la metodología empleada y al entendimiento del proceso de desarrollo del niño.

PALABRAS-CLAVE: educación - educación física - capoeira - práctica pedagógica trato con el conocimiento.

136 NORONHA, F. D. A.; NUNES PINTO, R. Capoeira nas aulas de educação... 


\section{NOTAS}

1 Esta composição pode ser variada conforme a linha, Angola ou Regional, que se segue. No nosso caso somos praticantes do estilo Angola e por este nos orientamos.

2 Para "ladainha" adotamos como explicação o tipo de canto que parece uma narração, um momento que se conta uma história e se manda uma mensagem para aqueles que vão jogar. Para "chula" colocamos como o momento de oração e de se pedir proteção. Para "corrido" adotamos a explicação do momento em que se inicia o jogo, sendo a música que embala mensagens para aqueles que estão na roda, seja jogando ou observando.

\section{REFERÊNCIAS}

ARAÚJO, R. C. A África e a afro-ascendência: um debate sobre a cultura e o saber. In: SILVA, C. (Org.). Ações afirmativas em educação: experiências brasileiras. São Paulo: Summus, 2003.

BASTOS, A. A prática pedagógica da capoeira na escola a partir de elementos da teoria crítico-superadora. Graduação (licenciatura em Educação Física). Faculdade de Educação Física da Universidade Federal de Goiás. Goiânia, 1999.

CARVALHO JR., W. M. de. Capoeira: (re) historiando o Brasil. Goiânia: [Ed. do Autor], 1998.

Capoeira. In: KUNZ, E. (Org.). Didática da Educação Física. Ijuí: Unijuí, 1998.

Capoeira el na Educação Física. Sprint, ano XVI, n. 79: 10 14, jul/ago; 1996.

CASTRO JR., L. V. \& ABIB, P. R. J. Capoeira: intervenção e conhecimento no espaço escolar. In: Anais XI Congresso Brasileiro de Ciências do Esporte. Florianópolis, v. 21, n.1, caderno 2, 1999, p. 177-183.

FARIA FILHO, L. M. de. História da escola primária e da Educação Física no Brasil: alguns apontamentos. In: SOUSA, E. S. \& VAGO, T. M. (Orgs.). Trilhas e Partilhas: educação física na cultura escolar e nas práticas sociais. Belo Horizonte: Cultura, 1997.

FRIGÉRIO, Alejandro. Capoeira: de arte negra a esporte branco. Revista Brasileira de Ciências Sociais. v. 4 (10): 85-98, jun., 1989. 
LEONTIEV, A. N. Uma contribuição à teoria do desenvolvimento da psique infantil. In: VIGOTSKY, L. S. et al. Linguagem, desenvolvimento e aprendizagem. São Paulo: Ícone: Editora da Universidade de São Paulo, 1988.

NORONHA, Flávia D. A. Capoeira nas aulas de Educação Física: refletindo a identidade sócio-cultural. Graduação (licenciatura em Educação Física). Universidade Federal de Goiás, Goiânia, 2002.

PALAFOX, Gabriel Humberto Muñoz (Org.). Planejamento Coletivo do Trabalho Pedagógico - PCTP: a experiência de Uberlândia. Uberlândia: Casa do Livro; Linograf, 2002.

PINHO, J. Iê a capoeira... Iê tem fundamento, câmara! Especialização Lacto sensu. Universidade Federal de Santa Catarina, Centro de Desportos, Florianópolis, 1993.

REIS, Letícia V. S. $O$ mundo de pernas para o ar: a capoeira no Brasil. São Paulo: Publisher Brasil, 1997.

SANTOS, S. A. dos. A luta anti-racismo. Revista Toques d'Angola, ano I, n. 1, nov., 2003, p. 34-37.

SILVA, P. C. da C. Capoeira na Educação Física - Uma história que dá jogo... primeiros apontamentos sobre suas inter-relações. Revista Brasileira de Ciências do Esporte, v. 23, n. 1, p. 123-130, set. 2001.

VAGO, T. M. Das escrituras à escola pública: a educação física nas séries iniciais do ensino fundamental. In: SOUSA, E. S. \& VAGO, T. M. (Orgs.). Trilhas e Partilhas: educação física na cultura escolar e nas práticas sociais. Belo Horizonte: Cultura, 1997.

VIGOTSKY, L. S. et al. Linguagem, desenvolvimento e aprendizagem. São Paulo: Ícone: Editora da Universidade de São Paulo, 1988.

ZAGATTO, B. A formação na tradição africana. Revista Toques d' Angola, ano I, n ${ }^{\circ}$ 01, nov., 2003, p. 16-17.

Recebido: 30 de abril de 2004 Aprovado: junho de 2004

Endereço para correspondência Rua 802, Qd. 803, Lt. 35, casa 2 Vila Osvaldo Rosa - Goiânia - GO

E-mail: luacapu@yahoo.com

138 NORONHA, F. D. A.; NUNES PINTO, R. Capoeira nas aulas de educação... 